Editorial

\title{
Use of the Robson Classification System for the Improvement and Adequacy of the Ways of Delivery in Maternities and Hospitals. An Opportunity to Reduce Unnecessary Cesarean Rates
}

\author{
Uso da Classificação de Robson Para Melhorias e adequação das vias de \\ Parto nas Maternidades e Hospitais. Uma Oportunidade Para Reduzir o \\ Índice de Cesáreas Desnecessárias no Brasil
}

\author{
Carlos Henrique Mascarenhas Silva ${ }^{1} \quad$ Claudia Lourdes Soares Laranjeira ${ }^{1}$ \\ ${ }^{1}$ Department of Gynecology and Obstetrics, Mater Dei Hospital, Belo \\ Horizonte, MG, Brazil \\ Rev Bras Ginecol Obstet 2018;40:377-378.
}

In the last decade, childbirth care in Brazil has undergone profound changes, which when properly applied in the daily practice of doctors and administrators of maternity wards will undoubtedly bring a great benefit to our patients. During this period, we also had intense debates and questions, focused mainly on the high rates of cesarean deliveries throughout Brazil, and without any doubts this is a situation that really must change.

However, for an adequate decision making, it is imperative that the measures to be taken are based on reliable data and on a simple analysis, so that we have an easier way to reach the goal of adjusting the cesarean delivery rates. In this sense, stratifying each of the women who arrive at our hospitals for delivery is of fundamental importance. Monitoring the indications for cesarean delivery is an essential strategy, among other measures, to achieve cesarean delivery rates at the appropriate levels. Over the years, several classifications have been tried. ${ }^{1}$

In 2001 , Robson ${ }^{2,3}$ proposed a way to classify pregnant women into 10 distinct groups, which are fully inclusive and mutually exclusive. Based on the characteristics of each pregnant woman, each patient can be included in one of the groups, but none of them can be included at the same time in more than one of the groups. The bases of these groups are five obstetric characteristics, obtained at the time of hospitalization for childbirth (-Table $\mathbf{1}$ ):

1. -Parity

2. -Gestational age at admission

3. -Moment of the onset of labor (before or after the admission)

4. -Fetal presentation

5. -Number of fetuses

Address for correspondence Carlos Henrique Mascarenhas Silva, Department of Gynecology and Obstetrics, Mater Dei

Hospital, Rua Gonçalves Dias,

2.700, 30190-094, Belo

Horizonte, MG, Brazil

(e-mail: carloshenrique@materdei.

com.br).
After being classified, the group of pregnant/puerperal patients of each hospital can be evaluated and compared with each other, creating strategies and protocols for the adequacy of the way of delivery. We can also compare health institutions, states and countries between public and private

Table 1 The 10 groups of the Robson Classification System

\begin{tabular}{|l|l|}
\hline Groups & Descriptions \\
\hline $\mathbf{1}$ & $\begin{array}{l}\text { Nulliparous, single cephalic, } \geq 37 \text { weeks, } \\
\text { in spontaneous labor }\end{array}$ \\
\hline $\mathbf{2}$ & $\begin{array}{l}\text { Nulliparous, single cephalic, } \geq 37 \text { weeks, } \\
\text { induced or CS before labor }\end{array}$ \\
\hline $\mathbf{3}$ & $\begin{array}{l}\text { Multiparous (excluding previous CS), } \\
\text { single cephalic, } \geq 37 \text { weeks, in spontaneous } \\
\text { labor }\end{array}$ \\
\hline $\mathbf{4}$ & $\begin{array}{l}\text { Multiparous (excluding previous CS), } \\
\text { single cephalic, } \geq 37 \text { weeks, induced or } \\
\text { CS before labor }\end{array}$ \\
\hline $\mathbf{5}$ & Previous CS, single cephalic, $\geq 37$ weeks \\
\hline 6 & All nulliparous breeches \\
\hline 7 & All multiparous breeches (including previous CS) \\
\hline 8 & All multiple pregnancies (including previous CS) \\
\hline $\mathbf{9}$ & All abnormal lies (including previous CS) \\
\hline $\mathbf{1 0}$ & $\begin{array}{l}\text { All single cephalic, } \leq 37 \text { weeks } \\
\text { (including previous CS) }\end{array}$ \\
\hline
\end{tabular}

Abbreviation: CS, cesarean section.

Copyright $\odot 2018$ by Thieme Revinter Publicações Ltda, Rio de Janeiro, Brazil

License terms 10.1055/s-0038-1668168. ISSN 0100-7203. 
care services or even between different times of the same obstetric unit.

In addition, each hospital/maternity can establish performance criteria in each group of patients. We know that the largest groups of pregnant women are concentrated in groups 1 to 5 , but the greatest opportunities for having a vaginal delivery are in the patients of groups 1, 3 and 4 . Strategically, when a patient enters a maternity hospital, the whole care team should focus on offering the best opportunities and conditions for these pregnant women to have a vaginal delivery.

On the other hand, the greatest risks of cesarean delivery may be concentrated in group 2 (nulliparous, $>37$ weeks, no labor or hospitalization for elective cesarean section), either because the pregnant woman is hospitalized for an elective cesarean section or due to the risk of failure of the labor induction if the induction criteria are not well defined and discussed with the obstetric team. For this reason, each obstetrical service must establish strict assistance protocols and well-defined criteria to minimize such risks

Another possible conclusion that was reached after using this classification is that due to the high rates of cesarean deliveries observed in recent years in Brazil, we will still have a large number of patients in group 5 arriving in maternity hospitals throughout the country for the next few years. We will only see a reduction in the number of patients in this group if we achieve a reduction of the current cesarean rates. ${ }^{4}$ In addition, clear criteria and guidelines must be created for this group of women, as we are currently seeing an increase in the desire to attempt to have a vaginal delivery after a previous cesarean section, due to the cultural and assistance shift that we are going through, requiring a welltrained and safe care team specific to this situation.

The characterization of the pregnant population of each institution, according to the Robson groups, is also essential for the implementation of care protocols, with well-defined criteria for each segment. A good protocol implementation and follow-up process can lead to the rapid, safe and longlasting reduction of unnecessary cesarean sections.

In this process, it is indispensable that the neonatal results do not get worse. It is very important that the institution does not transform the objective of reducing the amount of cesarean deliveries in performing more "vaginal deliveries at any cost." Obstetric perineal injury rates, admission of newborn infants to neonatal intensive care units, Apgar scores lower than 7 in the 5th minute, and maternal and fetal death rates should be kept under constant monitoring and with strict targets.
The discussion of these results with the physicians and the whole health team assisting the pregnant woman is fundamental to this process of paradigm shift that we are experiencing, involving not only technical and assistance issues, but also strong cultural componentes. ${ }^{5}$ We cannot forget to listen to the opinion of the women to know their level of satisfaction and their experience with the process of childbirth.

Since the proposal of this classification, several obstetrical services have started to test the Robson classification system in different scenarios. ${ }^{3}$ In 2015, the World Health Organization used the classification in a multicenter study of cesarean sections and considered it an important tool for the knowledge of the maternity population and the quality of the information available, and these criteria are important in strategies to reduce unnecessary cesarean deliveries. ${ }^{6}$

Because of the ease of implementation and interpretation, the Robson classification system is undoubtedly an important tool for the clinical and administrative management of maternities, contributing to the knowledge of the assisted populations and the subsequent organization of obstetric care.

\section{Conflicts of Interest}

The author has no conflict of interests to declare.

\section{References}

1 Torloni MR, Betran AP, Souza JP, et al. Classifications for cesarean section: a systematic review. PLoS One 2011;6(01):e14566. Doi: 10.1371/journal.pone.0014566

2 Robson MS. Classification of caesarean sections. Fetal Matern Med Rev 2001;12:23-39. Doi: 10.1017/S0965539501000122

3 Robson MS. Can we reduce the caesarean section rate? Best Pract Res Clin Obstet Gynaecol 2001;15(01):179-194. Doi: 10.1053/ beog.2000.0156

4 Brennan DJ, Robson MS, Murphy M, O’Herlihy C. Comparative analysis of international cesarean delivery rates using 10-group classification identifies significant variation in spontaneous labor. Am J Obstet Gynecol 2009;201(03):308.e1-308.e8. Doi: 10.1016/ j.ajog.2009.06.021

5 Robson M, Hartigan L, Murphy M. Methods of achieving and maintaining an appropriate caesarean section rate. Best Pract Res Clin Obstet Gynaecol 2013;27(02):297-308. Doi: 10.1016/j. bpobgyn.2012.09.004

6 Vogel JP, Betrán AP, Vindevoghel N, et al; WHO Multi-Country Survey on Maternal and Newborn Health Research Network. Use of the Robson classification to assess caesarean section trends in 21 countries: a secondary analysis of two WHO multicountry surveys. Lancet Glob Health 2015;3(05):e260-e270 